\title{
PROMOSI DAN SUMBER DAYA MANUSIA TERHADAP KEPUASAN KONSUMEN DAMPAKNYA PADA LOYALITAS KONSUMEN DI TOKO SOES MERDEKA
}

\author{
Dina Febe Kristanti \\ Wasito \\ wasitohardjo@yahoo.co.id \\ Fakultas Ekonomi dan Bisnis, Universitas Pasundan
}

diterima: 29/7/2017; direvisi: 8/8/2017; diterbitkan: 24/2/2018

\begin{abstract}
This study aims to determine how much influence of promotion and human resources (HR) at SoesMerdeka store towards consumer loyalty through the satisfaction of the customer as an intervening variable either partially or simultaneously. The research method used is descriptive and verification method with the number of samples counted to 98 respondents. Data collection techniques used were observation and distribution of questionnaires, and analysis methods used are path analysis, multiple correlation, and coefficient of determination. The result shows that promotion, human resource, consumer satisfaction, and consumer loyalty are in enough category. The results of verification research shows promotion and human resources to consumer satisfaction has an influence of 55\%, promotion, human resources, and consumer satisfaction on consumer loyalty has an influence of $43.3 \%$.
\end{abstract}

Keywords : promotion; HR; consumer satisfaction; consumer loyalty

\begin{abstract}
Abstrak
Penelitian ini bertujuan untuk mengetahui seberapa besar pengaruh promosi dan SDM (Sumber Daya Manusia) pada toko Soes Merdeka terhadap loyalitas konsumen melalui kepuasan kosumen sebagai variabel intervening baik secara parsial maupun simultan. Metode penelitian yang digunakan adalah metode deskriptif dan verifikatif dengan jumlah sampel sebanyak 98 responden. Teknik pengumpulan data yang digunakan adalah observasi dan penyebaran kuesioner, dan metode analisis jalur (path analysis), korelasi ganda dan koefisien determinasi. Hasil penelitian deskriptif terhadap produk toko Soes Merdeka menunjukkan bahwa rata-rata promosi, SDM, kepuasan konsumen, dan loyalitas konsumen berada dalam kategori cukup. Hasil penelitian verifikatif menunjukkan pengaruh promosi dan SDM terhadap kepuasan konsumen sebesar $55 \%$ dan pengaruh promosi, SDM, dan kepuasan konsumen terhadap loyalitas konsumen sebesar 43,3\%.
\end{abstract}

Kata Kunci : promosi; SDM; kepuasan konsumen; loyalitas konsumen 


\section{PENDAHULUAN}

Bisnis menciptakan banyak peluang berdasarkan kreatifitas dan inovasi yang ditampilkan dengan melibatkan beberapa orang guna menghasilkan jasa atau produk yang dibutuhkan konsumen. Bisnis dilakukan dengan cara manual maupun maupun memanfaatkan teknologi canggih sebagai sarana produksi dengan melibatkan aspek-aspek manajemen, financial, marketing, human resources. Salah satu contoh usaha bisnis yang ada dan masih berjalan sampai saat ini yaitu bisnis makanan yang saat ini bervariasi, tidak hanya lauk pauk atau makanan pokok saja, melainkan berupa roti, kue, mulai dari kue tradisional sampai makanan mancanegara yang mulai digemari masyarakat Indonesia. Roti dan Kue, sering dijadikan konsumsi sehari-hari sehingga membuat makanan jenis ini laris manis.

Banyaknya toko roti dan kue yang berkembang pesat di Bandung dengan persaingan di bidang bisnis sejenis semakin ketat, karena disebabkan oleh banyaknya pilihan hidangan roti maupun kue dengan variasi bentuk serta rasa, tekstur, maupun harga yang sesuai dengan kualitas produk yang dihadirkan.

Hal ini membuat para pengusaha dalam bidang ini berlomba-lomba untuk menjadi yang terdepan dalam bidangnya, dan hal ini pula memacu para pengusaha kuliner untuk menetapkan orientasi kepuasan konsumen sebagai tujuan utamanya untuk menjaga kelangsungan perusahaan tersebut. Keadaan ini tampak dari banyaknya perusahaan yang menyertakan komitmennya terhadap kepuasan konsumen dalam pernyataan visi dan misi. Dalam pasar yang tingkat persaingannya cukup tinggi, perusahaan mulai bersaing untuk memberikan kepuasan kepada pelanggannya agar pelanggan mempunyai kesetiaan yang tinggi terhadap kue, roti maupun soes yang ditawarkan pengusaha. Apabila pelanggan merasa tidak puas maka pelanggan tersebut tidak akan kembali lagi pada perusahaan tersebut.

Loyalitas pelanggan erat hubungannya dengan kepuasan konsumen, semakin terpuaskan konsumen terhadap keinginannya, atau terpuaskan antara harapan dengan kenyataan, akan membuat konsumen kembali lagi untuk membeli produk tersebut dan konsumen yang loyal terhadap produk itu. Sedangkan kepuasan pelanggan dipengaruhi oleh pelayanan karyawan yang baik, adanya reputasi dari penjual dan adanya kualitas produk yang sesuai dengan harapan konsumen.

Dengan semakin berkembangnya bisnis di bidang usaha Kue dan Roti di Bandung, pihak Soes Merdeka Bandung harus berjuang keras dalam mempertahankan pelanggan yang sudah ada. Hal tersebut sangat penting karena adanya persaingan yang sangat ketat dari para pelaku bisnis kue dan roti lainnya, yang masing-masing pelaku bisnis berusaha menampilkan ciri-ciri produk yang dihasilkan, karakter dan identitas toko, kualitas dan keunggulan produk mulai dari kelezatan soes, kue dan roti itu sendiri, varian rasa, variasi ukuran dan bentuk, ketebalan dan keempukan roti yang berbeda dari outlet toko kue dan roti lainnya.

Tabel 1. Data Outlet Toko Kue dan Roti di Kota Bandung

\begin{tabular}{|c|c|c|}
\hline $\begin{array}{l}\text { Nama } \\
\text { Outlet }\end{array}$ & $\begin{array}{c}\text { Jumlah } \\
\text { Toko }\end{array}$ & Alamat \\
\hline $\begin{array}{l}\text { Soes } \\
\text { Merdeka }\end{array}$ & 2 & $\begin{array}{l}\text { - Jl. Merdeka No.27 Telp.(022)4235534 } \\
\text { Bandung } \\
\text { - J1. Lombok No.30 Telp.(022)4204746 } \\
\text { Bandung }\end{array}$ \\
\hline Primarasa & 5 & $\begin{array}{l}\text { - Jl. Kemuning No.20 Merdeka Sumur } \\
\text { Bandung No.Telp.(022)7206468 } \\
\text { - J1. Buah batu No.167 A Telp. } \\
(022) 7311537 \\
\text { - J1. Pasirkaliki No.163 No.Telp } \\
(022) 6120177 \\
\text { - Jl. Purwakarta No.95 Antapani Kota } \\
\text { Bandung } \\
\text { - Ruko Kopo Plata Block C-6 Jl. Peta } \\
\text { Lingkar Selatan }\end{array}$ \\
\hline
\end{tabular}

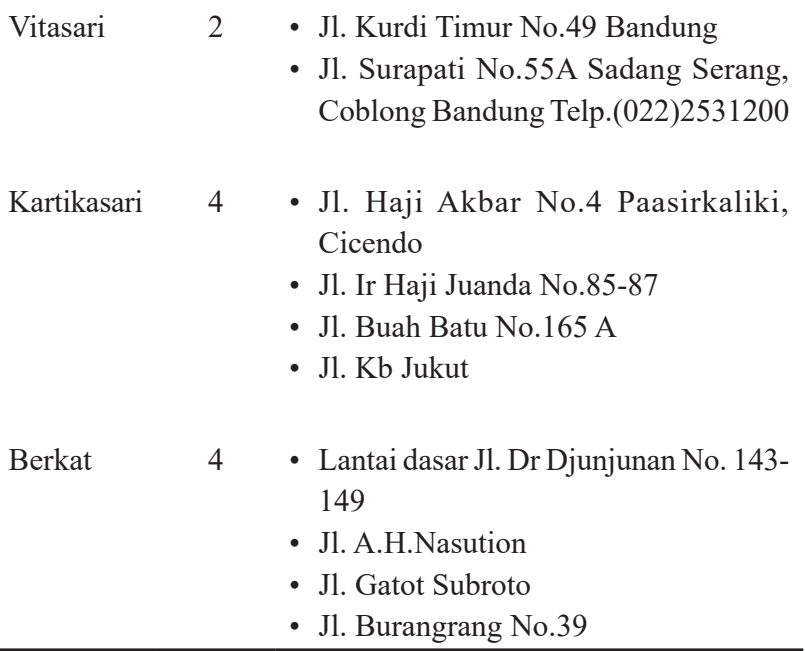

Sumber: www.google.co.id

Hal ini membuat para pengusaha dalam bidang ini berlomba-lomba untuk menjadi yang terdepan dalam bidangnya, dan hal ini pula memacu para pengusaha kuliner untuk menetapkan orientasi kepuasan konsumen sebagai tujuan utamanya untuk menjaga kelangsungan perusahaan tersebut.

Tabel 2. Data penjualan di Toko Soes Merdeka di Kota Bandung Periode Tahun 2013-2015

\begin{tabular}{cc}
\hline Tahun & Jumlah Penjualan \\
\cline { 2 - 2 } & (rupiah) \\
\hline 2013 & 5.767 .315 .000 \\
2014 & 5.322 .653 .000 \\
2015 & 4.317 .465 .150 \\
\hline
\end{tabular}

Sumber: Toko Soes Merdeka 
Pada Tabel 2 terlihat adanya penurunan pada jumlah penjualan yang diperoleh oleh di Toko Soes Merdeka Bandung selama 3 tahun terakhir dengan penurunan yang dari tahun 2013 ke tahun 2014 sebesar Rp 444.662.000, dan penurunan terjadi lagi dari tahun 2014 ke tahun 2015 sebesar Rp 1.005.187.850. Penurunan ini tentu saja sangat mempengaruhi laba di Toko Soes, Roti dan Kue Merdeka Bandung dalam perkembangan usahanya.

\section{METODE}

Peneliti mengumpulkan data yang berupa informasi yang berhubungan dengan masalah yang akan diteliti untuk menjawab rumusan masalah baik yang bersifat deskriptif maupun verifikatif selain itu untuk membuktikan apakah hipotesis penelitian diterima atau ditolak. Penelitian yang digunakan adalah penelitian deskriptif dan verifikatif.

Penelitian deskriptif digunakan untuk mengetahui tanggapan responden tentang variabel-variabel yang diteliti yang meliputi pelaksanaan promosi, SDM, kepuasan konsumen, dan loyalitas konsumen. Penelitian verifikatif digunakan untuk mengetahui besar pengaruh promosi dan SDM terhadap kepuasan konsumen serta pengaruh kepuasan konsumen terhadap loyalitas konsumen serta untuk mengetahui pengaruh variabel independen terhadap variabel dependen baik secara langsung maupun tidak langsung melalui variabel intervening.

\section{HASIL DAN PEMBAHASAN}

PT Tirta Ratna didirikan berdasarkan akta No. 126 Tanggal 31 Mei 1969 yang dibuat di hadapan Notaris Koswara, SH. Sebelumnya, perusahaan ini dipegang oleh Pemerintah Daerah Bandung (PEMDA) yang bernama PD MAMIN (Perusahaan Daerah Makanan dan Minuman). Pada saat Indonesia merdeka, PD MAMIN diambil alih oleh PEMDA Bandung dari tangan Belanda. Sebenarnya, perusahaan ini sudah ada sejak zaman penjajahan untuk memenuhi kebutuhan penjajah dan ekspaktriat. Saat itu hanya memproduksi soes, karena soes merupakan makanan yang berasal dari Eropa. Banyak diantara kalangan karyawan yang tidak memiliki kecocokan dengan sistem yang digunakan oleh Pemerintah Daerah, sehingga para karyawan tersebut memutuskan untuk bergabung dan membentuk suatu perusahaan swasta yakni PT Tirta Ratna.

Pada awalnya, usaha utama yang dilakukan adalah produksi soes, seiring dengan berkembangnya perusahaan serta permintaan pasar, usaha PT Tirta Ratna merambah ke jenis makanan lainnya seperti bakery, pastry, cake, snack kering, jajanan pasar, air minum dalam kemasan, sosis dan daging olahan, hingga ke bisnis non-pangan yakni properti dan travel. Perusahaan ini didirikan diatas lahan seluas $8000 \mathrm{~m} 2$, yang terbagi menjadi dua buah bangunan untuk kantor $(6000 \mathrm{~m} 2)$ dan ruang produksi serta Toko Soes Merdeka (2000 m2) di Jalan Merdeka no. 25-29 Bandung, Jawa Barat.

Berikut adalah hasil persentase berdasarkan jenis kelamin :

Tabel 4. Jenis Kelamin

\begin{tabular}{ccc}
\hline Keterangan & Frekuensi & Persentase \\
\hline Laki-laki & 30 & 30,6 \\
Wanita & 68 & 69,4 \\
Total & 98 & 100,0 \\
\hline
\end{tabular}

Sumber: pengolahan data primer 2016

Berdasarkan Tabel 4 dapat diketahui bahwa mayoritas konsumen Toko Soes Merdeka adalah wanita dengan persentase $69,4 \%$, hal tersebut dinyatakan menurut Ujang S (2014:290) kaum wanita merupakan konsumen potensial yang membeli begitu banyak barang dan jasa. Maka dapat dikatakan, karena wanita yang lebih sering melakukan transaksi belanja barang maupun jasa meskipun hanya melakukan pembelian berupa kue, roti dan cemilan lainnya. Wanita yang sudah menjadi ibu rumah tangga melakukan pembelian di Toko Soes Merdeka untuk kebutuhan rumah tangga, sedangkan wanita karir muda maupun mahasiswa melakukan pembelian di Toko Soes Merdeka karena remaja senang ngemil.

Tanggapan konsumen terhadap promosi di Toko Soes Merdeka kurang maksimal karena masih ada indikator di bawah rata-rata yaitu Situs web Soes Merdeka membantu pelanggan dalam mendapatkan informasi, pesan mengenai produk yang disampaikan dapat dengan mudah dimengerti oleh konsumen dan pemberian potongan harga oleh Toko soes Merdeka mempengaruhi pelanggan dalam memilih Toko soes merdeka. Tanggapan konsumen terhadap SDM pada Toko Soes Merdeka yaitu pelayanan dari SDM pada Toko Soes Merdeka masih kurang baik karena masih ada indikator di bawah rata-rata yaitu karyawan ramah dalam melayani konsumen dan karyawan berpenampilan dengan baik dan sopan; Tanggapan konsumen tentang kepuasan pada Toko Soes Merdeka yaitu konsumen masih merasa kurang puas dikarenakan masih ada indikator di bawah ratarata yaitu kesesuaian kualitas layanan dengan harapan, kesesuaian kualitas produk dengan harapan, kepuasan dari berbagai pilihan produk, dan kesesuaian rasa produk Soes Merdeka dengan harapan. Tanggapan konsumen tentang loyalitas pada Toko Soes Merdeka yaitu konsumen masih merasa kurang loyal pada toko Soes Merdeka, dikarenakan masih ada indikator di bawah rata-rata yaitu membeli roti, kue, jajanan pasar selain dari produk andalannya soes dan sangat sering melakukan pembelian ulang di Toko Soes Merdeka. 
Hasil penelitian dan uji hipotesis didapatkan hasil bahwa promosi dan SDM berpengaruh terhadap kepuasan konsumen secara simultan dan parsial. Hasil ini sesuai dengan penelitian Thjahjaningsih (2012), Abbas (2015), Lumintang (2015), Lumbantobing (2013), Widjoyo (2014). Hal ini menunjukkan bahwa semakin baik promosi dan SDM maka tingkat kepuasan konsumen terhadap produk di Toko Soes Merdeka akan meningkat. Secara simultan promosi, SDM dan kepuasan konsumen berpengaruh secara signifikan terhadap loyalitas konsumen. Hasil ini sesuai dengan penelitian Ayuniartika dan Doeranto (2014), Widjoyo (2014).

Kepuasan konsumen dapat mempengaruhi loyalitas konsumen secara langsung sedangkan promosi tidak mempengaruhi loyalitas konsumen, melainkan promosi dapat mempengaruhi loyalitas konsumen melalui kepuasan konsumen sebagai variabel intervening. Promosi mempengaruhi loyalitas konsumen melalui kepuasan konsumen dan tidak mempengaruhi loyalitas konsumen secara langsung. SDM dapat mempengaruhi loyalitas konsumen secara langsung ataupun melalui kepuasan konsumen karena baik secara langsung maupun tidak langsung SDM memiliki nilai yang signifikan.

\section{KESIMPULAN}

Berdasarkan hasil dan pembahasan yang telah dilakukan, diperoleh kesimpulan: (1) Tanggapan konsumen tentang promosi di Toko Soes Merdeka kurang maksimal, pelayanan kurang baik, konsumen kurang puas, dan kurang loyal; (2) Promosi dan SDM berpengaruh secara simultan maupun parsial terhadap kepuasan konsumen; (3) Promosi, SDM, dan kepuasan konsumen berpengaruh secara simultan terhadap loyalitas konsumen, akan tetapi promosi tidak berpengaruh langsung terhadap loyalitas konsumen.

\section{DAFTAR PUSTAKA}

Abbas, F. 2015. Pengaruh Marketing Mix Terhadap Kepuasan Konsumen (Pada Home Industry Moshimoshi Cake Samarinda), JURNAL ADMINISTRASI BISNIS, VOL 3, NO 1, Edisi 2015, 3 (1): 244-258 (ISSN : 2355-5408)

Ayuniartika dan Doeranto, P. 2014. Analisis Pengaruh Penerapan Bauran Pemasaran Terhadap Loyalitas Konsumen Untuk Membeli Produk dengan Metode Regresi Linier Berganda (survey pada Ayam Bakar Wong Solo Cabang Malang).

Endang Tjahjaningsih. 2012. Pengaruh Citra dan Promosi Terhadap Kepuasan Konsumen Serta Dampaknya Terhadap Loyalitas Konsumen (studi pada Pelanggan Supermarket Carrefour di Semarang), JURNAL ADMINISTRASI BISNIS, VOL 4, NO 1, Edisi 2012, 1 (4): 340-350 (ISSN :0000-0000).

Jill, G. 2010. Customer Loyalty. Erlangga, Jakarta.

Kotler, Philip and Kevin Lane Keller, 2012, Marketing Management, (14th Edition), New Jersey: Prentice Hall Published.

Kotler, Philip and Gary Amstrong, 2014, Principles Of Marketing, (15th Edition), New Jersey: Pearson Prentice Hall.

Lumbantobing, M, Melda. 2013. Pengaruh Prestise, Persainga, dan Bauran Pemasaran 7P terhadap Kepuasan Konsumen Fountain Ice Cream Cafe Plaza. Lumintang, G. 2015. Analisis Kualitas Produk dan Kualitas Layanan Terhadap Kepuasan Konsumen pada Holland Bakery Boulevard Manado.

Widjoyo, S. 2014. Pengaruh Kualitas Layanan dan Kualitas Produk Terhadap Kepuasan Konsumen dan Loyalitas Konsumen Restoran Happy Garden Surabaya.

www.soesmerdeka.co.id www.google.co.id 


\begin{tabular}{|c|c|c|}
\hline Variabel dan Konsep Variabel & Dimensi & Indikator \\
\hline \multirow{3}{*}{$\begin{array}{l}\text { Promosi (X1) } \\
\text { Promosi mengacu pada kegiatan yang } \\
\text { mengkomunikasikan manfaat produk } \\
\text { dan membujuk konsumen sasaran untuk } \\
\text { membeli. } \\
\text { Kotler dan Amstrong (2014:76) }\end{array}$} & 1. Pesan & $\begin{array}{l}\text { 1. Pesan mengenai produk yang disampaikan dapat dengan mudah } \\
\text { dimengerti oleh konsumen }\end{array}$ \\
\hline & 2. Media Promosi & $\begin{array}{l}\text { 1. Media promosi yang digunakan dapat menarik konsumen dan } \\
\text { diingat konsumen }\end{array}$ \\
\hline & 3. Alat Promosi & $\begin{array}{l}\text { 1. Situs web Soes Merdeka membantu pelanggan dalam mendapatkan } \\
\text { informas } \\
\text { 2. Pemberian potongan harga oleh Toko Soes Merdeka } \\
\text { 3. Layanan rekomendasi dari konsumen lain yang pernah membeli } \\
\text { di Toko Soes Merdeka }\end{array}$ \\
\hline
\end{tabular}

SDM (X2)
Orang (people) adalah semua pelaku

yang memainkan peranan penting dalam penyajian jasa sehingga dapat mempengaruhi persepsi pembeli.

Kotler dan Amstrong (2012:62)

$\begin{array}{ll}\text { 1. Sikap } & \text { 1. Karyawan ramah dalam melayani konsumen } \\ & \text { 2. Karyawan berpenampilan dengan baik dan sopan }\end{array}$

2. Komunikasi

1. Karyawan menyampaikan informasi produk dengan jelas

2. Karyawan menyampaikan informasi produk dengan bahasa yang baik
Kepuasan Konsumen (Y)
Perasaan senang atau kecewa seseorang yang muncul setelah membandingkan antara kinerja (hasil) produk yang diprakirakan terhadap kinerja (hasil) yang diharapkan.

Kotler dan Keller (2012;177)

\section{Kinerja}

1. Kepuasan atas keramahan karyawan dalam melayani konsumen

2. Kepuasan atas kinerja karyawan dalam melayani dengan tepat

3. Kepuasan atas kinerja karyawan dalam melayani dengan cepat

4. Kepuasan dari berbagai pilihan produk

5. Kepuasan rasa dari produk Soes Merdeka

2. Harapan
1. Kesesuaian rasa produk Soes Merdeka dengan harapan

2. Kesesuaian kualitas produk dengan harapan

3. Kesesuaian kualitas layanan dengan harapan
Loyalitas Konsumen $(\mathrm{Z})$

Komitmen pelanggan bertahan secara mendalam untuk berlangganan kembali atau melakukan pembelian ulang secara konsisten dimasa yang akan datang, meskipun pengaruh situasi dan pemasaran menyebabkan perubahan perilaku.

Jill Griffin

(2010:129)

\section{Membeli ulang \\ 1. Melakukan pembelian ulang secara teratur}

2. Membeli lini produk 1. Pembelian produk atau jasa lain atau jasa lain

\begin{tabular}{ll}
\hline $\begin{array}{l}\text { 3. Mereferensikan } \\
\text { kepada orang lain }\end{array}$ & $\begin{array}{c}\text { 1. Memberikan saran kepada orang lain atau merekomendasikan } \\
\text { tentang produk }\end{array}$ \\
\hline $\begin{array}{l}\text { 4. Tidak mudah } \\
\text { tertarik dengan } \\
\text { produk pesaing }\end{array}$ & 1. Menolak terhadap prodak pesaing \\
\hline
\end{tabular}

